\title{
Üniversite Sıralamalarında Metodoloji: Gerçekte Ölçülen Ne?
}

\author{
Hasan Okuyucu \\ Ankara Yılııım Beyazit Üniversitesi, Mühendislik ve Doğa Bilimleri Fakültesi, Metalurji ve Malzeme Mühendisliği Bölümü, Ayvalı Mah. Takdir Cad. \\ 150 Sk. No: 5 Etlik-Keçiören / Ankara \\ ORCID: H.Okuyucu (0000-0002-4977-6980)
}

\begin{abstract}
Özet
Üniversite sıralamaları son yıllarda oldukça popüler hale geldi. İlk İngiltere ve ABD merkezli kuruluşların başlattığı sıralama günümüzde yüzden fazla kurum tarafından yapılmaktadır. Çok sayıda sıralama yapan kurum olmasına rağmen sıralama yapan kurulușların sıralamaya veri olarak kullandıkları bilgiler Web of Science, Scopus ve Google Scholar gibi akademik yayın verilerini kayıt eden kurumlardan temin edilmektedir. Bu çalışmada sıralama yapan kurumlardan 3 tanesi seçilmiş ve bu sıralamalarda kullanılan metodoloji irdelenmiștir. Seçilen kriterlerin ağırlıkları, nasıl bilgi toplandığı ve nihai puanlamaların nasıl yapıldığı açıklanmıştır. Sıralama metodunun üniversitenin fonksiyonu olan ArGe-Eğitim-topluma katkı unsurlarını nasıl ölçtŭğü ve bu bağlamda kaliteyi nasıl yansıttığı tartışılmıştır.
\end{abstract}

Anahtar kelimeler: Sıralama, Üniversite, ArGe, Kalite.

\section{Methodology for University Ranking: What is really measured?}

\begin{abstract}
University ranking has been popularized recently. UK and USA based institutions have started to make ranking initially then became widespread globally. Even though there has been several institutions which make University ranking, data that are used for ranking is supplied by limited institutions like Web of Science, Scopus and Google Scholar. In this study, three ranking institutions are selected and their methodologies are examined. Proportions of criteria, the way of data collection and the final scoring are also examined. Measuring the quality of University's three main functions that are $R \& D$, education and the contribution to the society is also examined.
\end{abstract}

Key words: Ranking, R\&D, Quality, and University

\section{Giriș}

Üniversiteler arasında tarih boyunca bir yarış ve rekabet olmuştur. Doksanlı yıllarda yükseköğretimde uluslararaSı öğrenci piyasasının büyümesi ile birlikte yarış daha da hızlanmış ve pazarın büyümesi ile birlikte üniversite sıralamalarına temel teşkil edecek araştırmaların yapılması gelişmeye başlamıştır. Uluslararası öğrenci pazarından daha fazla pay kapmak ve Dünya çapında başarılı üniversiteler oluşturmak isteyen ülkelerin kurduğu üniversiteler arasındaki yarış gün geçtikçe kızışmaktadır. Üniversite sıralamalarının, üniversitenin kalitesini ölçmede kullanılması halen tartışılmakta olmasına rağmen idareci ve politika yapıcılar geleceğe dair planlamalar yaparken bu sıralamaları kullanmaktadırlar (Pike, 2004)(Saisana, D'Hombres, \& Saltelli, 2011).

*Yazışma Adresi / Address for Correspondence: Hasan Okuyucu, Email: okuyucu@ybu.edu.tr

Geliş Tarihi / Received Date: 01.04.2019

Kabul Tarihi / Accepted Date: 06.08.2019

Doi: $10.26701 /$ uad. 547779
Verilen eğitimin kalitesinin de gerek yerel gerek se uluslararası ölçekte belirlenmesi ya da ölçülmesi hizmet kalitesi bakımından önemli bir göstergedir. Hizmet kalitesine gösterge olması amacıyla yapılan Üniversite sıralamaları, her yükseköğretim kurumunun kendine has bir misyonu ve ilgi alanı olmasına ve farklı akademik programları bulunması sebebi ile ciddi zorluk içermektedir. Bu zorluklar sebebi ile yapılan genel sıralamaların yanında program sıralamaları da yapılmaktadır.

Sıralama yapanlar Üniversite sıralamalarını, bu sıralamayı kullananlardan bazıları farklı amaçlarla kullansalar da başlangıçta yükseköğretimin verimliliğini değerlendirmek için tasarlamışlardır. Çoğu zaman üst sırada yer alan yükseköğretim kurumlarının daha alt sıralardaki yükseköğretim kurumlarına nazaran daha üretici, eğitim ve ArGe kalitesi bakımından daha iyi ve topluma katkısının daha fazla olduğu kabul edilir. Oysa bir üniversitenin 3 fonksiyonu -eğitim-ArGe - topluma hizmet- birbirinden farklılık arz edebilir ve biri diğerini olumsuz da etkileyebilir. Yani bu fonksiyonlardan birini çok iyi yapan bir yükseköğretim kurumu, diğerini yapmada aynı başarıyı 
gösteremeyebilir. Mesela sınırlı kaynaklara sahip küçük bir yükseköğretim kurumu öğrencilerine kaliteli bir eğitim verebilir ancak verimli araştırmalar yapamayabilir. Bu durumun tersinin de mümkün olabileceği düşünülebilir.

Üniversite sıralamaları verilen hizmetin kalite ve verimliliği bakımından faydalı bazı bilgiler vermesine rağmen öğrenci isteklerini karşılayabilen eşitlik ve eğitimin misyonu bakımından eleştirel bazı düşünceleri de getirmektedir. Sıralamalar doğru olmayan bazı kavramlara yönlendirmektedir: bazı kurumlar kötü diğer bazıları da elit olarak etiketlenmektedir. Bu türden bir sıralama doğru kabul edilemez çünkü her yükseköğretim kurumu farklı tarihi kültürel ve toplumsal kurallar doğrultusunda eğitim-öğretim yapmaktadır (Harvey, 2008).

Bir tarafta potansiyel öğrencileri çekmek için yapılan ve bu bakımdan yükseköğretim kurumunu üst sıralarda gösterecek göstergeler kullanılarak yapılan siralamalar varken diğer tarafta yükseköğretim kurumunun verilen eğitimin etkinliğini ölçmek, öğrencilerin beklentilerini karşılamak gibi kalite ile doğrudan ilgili olan göstergeler seçilmeyebilmektedir.

Üniversite lisans ve yüksek lisans seviyesinde öğretim ve araştırma yapılan kurumdur. $\mathrm{Bu}$ duruma göre üniversitenin bu kavramları yerine hakkıyla getirmesi beklenir. Bu görevleri yerine getirebilmesi için de öğretim elemanlarının iyi olması ve araştırmacılarının da alanında bilimsel üretim bakımından verimli olması beklenir.

Eğitim ve araştırma kalitesini ölçen gerçekçi bir üniversite sıralaması ile tüketiciler için hazırlanan raporu birbirinden ayırt etmek gerekir. Gerçekçi bir sıralama üniversitelerin eğitim verme ve ArGe bakımından kalitesini ölmelidir. Öğrencilerin ilgisini çekecek bazı kriterleri dikkate alarak yapılan sıralamalar gerçek anlamda sıralama sayılamaz. Mesela üniversitelerin sosyal hayatının hareketliliği ya da kampüste kaliteli yiyecek sunulması gibi kriterler üniversite kalitesini doğrudan ilgilendiren konular olmamasına rağmen öğrencilere yönelik yapılan sıralamalarda bu hususlar kriter olarak ölçülmektedir.

Üniversite arayışında olan öğrenciler, sıralamalara bakarken beklentileri üniversitenin öğretim bakımından başarılı olması ve öğretim üyelerinin de alanlarında Dünya çapında başarılı olması gibi kriterlere de bakmaktadır. Öğretim ve ArGe bakımından üst sırada olan A üniversitesi ile öğretim ve ArGe bakımından A üniversitesi kadar başarılı olmayan ancak mesela uluslararası bilinirlik bakımından daha başarılı B üniversitesini karşılaştırdığında A üniversitesini tercih eden bir öğrenci kalite bakımından doğrudan üniversiteden beklenen kaliteyi esas alan bir kaliteyi değil uluslararası hareketliliği esas alan bir kaliteyi tercih etmiş olmaktadır. Çünkü B üniversitesi kalite bakımından daha düşük seviyeli bir üniversitedir (Taylor \& Braddock, 2007).

Üniversitenin öğretim ve ArGe kalitesi yerine uluslararası bilinirlik bakımından tercih edilmesi makul sayılabilir ancak uluslararası bilinirliğin kalite anlamına gelmediğini vurgulamak gerekir. Öğretim ve ArGe bakımından kaliteli olmadığı halde Uluslararası olarak bilinen üniversitelerden mezun olmak iş bulabilmek ve sosyal statü bak1mından getiri sağlayabilir ancak kaliteli bir üniversiteden eğitim aldığı söylenemez. Ayrıca öğretim ve ArGe bakımından kaliteli bir üniversitenin uluslararası anlamda bilinir olacağı söylenebilir ancak her uluslararası bilinir üniversitenin öğretim ve ArGe bakımından kaliteli olduğu söylenemez.

$\mathrm{Bu}$ sebeple sıralamalar dikkate alınırken üniversite kalitesi bakımından gerçek göstergelerin mi yoksa üniversite kalitesini tam anlamıla yansıtmayan önemsiz göstergelerin mi dikkate alındığına dikkat etmek gerekir.

\section{SIRALAMADA KRITER SEÇIMI VE KRITERLERIN AĞIRLIKLANDIRILMASI}

Üniversite sıralamaları yapılırken seçilen kriterlerde iki hususa dikkat etmek gerekmektedir; Üniversitenin kalitesine etkisi kuvvetli olan bir kriter ve bu kriterin ölçülebilir olması. Bazı kriterler ulusal anlamda ölçülebilmekte iken uluslararası anlamda ölçülmesi mümkün olmayan kriterler de mevcuttur. Üniversite kalitesini doğrudan etkileyen bir unsur olan mezunlarının işe yerleşme oranı bazı ülkelerde ölçülebilmekte iken ölçümün yapılmadığı ya da hassasiyetinin düşük olduğu ülkeler mevcuttur ve ölçüm yapan kurumların hiç birisi tarafından kullanılmamaktadır. Bu bakımdan özellikle uluslararası sıralama yapılırken seçilen kriterlerin her ülkenin üniversite bakımından seçilen kriterlerin uluslararasında ölçülebilecek kriterlerden seçilmelidir.

$\mathrm{Bu}$ çalışmada Türkiye'nin en bilinen sıralamalarından biri olan ve kriterlerini tamamen Uluslararası ölçülebilen akademik yayınlar üzerinden seçen URAP sıralaması (URAP, n.d.), kriter olarak akademik yayınlar haricinde en fazla kriter kullanan sıralamalardan biri olan Times Higher Education (THE) (Education, n.d.)ve 1983 yılından itibaren sıralama yapan ve üniversitenin yanında hastane, orta dereceli okul, şehir, tatil beldesi ve ticari tüketim alışkanlıkları gibi çeşitli alanlarda sıralama yapan ve Üniversite sıralamasında kriter olarak büyük oranda akademik yayınları esas alan US News and World Report (Ranking, n.d.) (Ranking, n.d.)sıralamaları incelenmek üzere seçilmiştir.

Sıralama yapılırken kriter seçiminin yanında sıralamanın isabetli olmasına katkı sağlayacak başka hususlar da vardır. Bir yükseköğretim kurumu için ArGe öğretimden daha mı önemlidir? Değerlendirme yapılırken ArGe'ye daha fazla ağırlık mı verilmelidir? Bu konuda bazı araştırmalar yapılmıştır. Yapılan bu çalışmalarda yükseköğretim kurumu yöneticilerine sorularak yükseköğretim kurumu sıralamalarında hangi unsurun ne ağırlıkta olması gerektiğine dair görüşlerine dayanmaktadır. Dolayısıyla her sıralama kuruluşunun farklı ağırlıklar kullanmasının yanında yükseköğretim kurumlarında görev yapan her 
yönetici de sıralamada kullanılan unsurlara değişen ağırlıklar verebilmektedir.

Sıralama yapan kurumların en eski ve köklülerinden olan THE üniversiteleri sıralarken Eğitim kalitesi, ArGe, üretilen akademik yayınlara yapılan atıflar, uluslararası işbirliği kabiliyeti ve endüstriyel geliri farklı oranlarda değerlendirerek sıralamaları hesap etmektedir. Bu kriterlerden Eğitim ana başlığı altında evrensel alanda bilinirlik, öğretim elemanı/öğrenci oranı, doktora öğrencisi mezun etme, doktoralı öğretim elemanına doktora sonrası çalışma yaptırma, üniversitenin fiziki imkânları ve akademik kapasitesini kullanarak elde ettiği gelir ana başlıkları eğitim kriterinin puanlamasında kullanılmaktadır.

US News Sıralama Kurumu da yapmış olduğu sıralamada yapmış olduğu araştırmaların uluslararası alanda bilinirliği, bölgesel alanda bilinirliği, akademik yayınlar, kitaplar, konferanslar, kurum akademik personelinin yapmış olduğu yayınlara yayın sahipleri dışındaki akademisyenlerin yaptıkları atıflar, toplam atıflar, en çok atıf yapılan yayın sayıları, uluslararası iş birlikleri, uluslararası işbirliklerinden türetilen yayınlar gibi kriterler geliştirilen formülasyon ile siralama puanları hesap edilmektedir.

Türkiye'de Orta Doğu Teknik Üniversitesi Bünyesinde faaliyet gösteren Akademik Performansa Dayalı Üniversite Sıralaması Kurumu (URAP) yapmış olduğu sıralamada yapılan akademik makale sayısı, makalelere yapılan atıfların sayısı, öğretim elemanlarının yapmış olduğu toplam yayın sayısı, akademik yayınların yapıldığı dergilerin etki oranları, atıfların yapılmış olduğu dergilerin etki oranları ve uluslararası işbirliği hususları ağırlıklandırılarak sıralamaları hesap etmektedir. Bu sıralamalarda kullanılan unsurlar ve bu unsurların sıralamada kullanılan ağırlıkları Tablo 1'de gösterilmiştir.

Üniversite siralamalarında kullanılan kriterlerin farklılıkları, değerlendirmeyi yapanların meslekleri ve ilgi alanları, bölgesel ihtiyaçlar, yükseköğretim kurumuna yüklenen farklı misyonlar, ülkelerin öncelikleri ve yükseköğretim kurumunun mali kaynakları göz önüne alındığında doğal karşılanmalıdır. Zira bir ülkede bulunan her üniversite farklı alanlarda verimli olmayı kendilerine misyon edinebilir. Bazı Üniversiteler uzay ve havacılık alanında yüksek seviyeli ArGe projelerini kendileri için öncelikli hedef edinirken, başka bazı üniversiteler yapabilirliği yüksek mezunlar yetiştirmeyi kendine hedef olarak seçebilir. Bazı üniversiteler daha çok teorik ArGe yaparken diğer üniversiteler endüstri ile doğrudan bağlantılı projeler gerçekleştirmek için imkânlarını yönlendirebilir.

THE ölçeğinde \%30'luk kısım eğitim-öğretime dair unsurlardan elde edilmektedir. 2016 yılında yapılan sıralamada bu başlıktaki oranın \%15'lik bilinirlik kısmı, 133 ülkeden 10323 kişi ile yapılan anket sonucunda oluşturulmuştur. Eğitim-öğretim kısmındaki diğer oranlar da Tablo 1'de görüldüğü gibi kurumun kendi fiziksel ve akademik şartlarına dayalı sayısal verilerden oluşmaktadır.
Bu kısımlar kurumun kendi beyanına dayalı kısımlardır. Diğer bir \%30'luk kısmı oluşturan ArGe ile ilgili, \%18'i oluşturan bilinirlik aynı şekilde ilgili kişilerle yapılan anketlerden oluşmaktadır. Kurumun kendi beyan ettiği ArGe gelirleri \%6'llk bir oran sıralama kriterinde etkin olmaktadır. ArGe gelirleri ülkelere, uygulanan ekonomik politikalara ve üniversitenin bulunduğu coğrafi konum dikkate alındığında ölçülmesi farklılık gösterebilecek ve ölçümü konusunda tam mutabakat sağlanamamış bir kriterdir. ArGe verimliliği de aynı şekilde \%6'lık bir kısmı oluşturmaktadır ve kurumun akademik kadrosuna göre yapmış olduğu yayınların verimini göstermektedir. Kurum akademik personelinin yapmış olduğu akademik çalışmalara diğer akademik çalışmalar tarafından yapılan atıflar THE sıralamasına \%30 oranında etki etmektedir. Akademik çalışmaların kalitesini göstermesi bakımından ve ölçülebilirliği yüksek oranda olduğu için Elsevier'in ilgili veri tabanlarından alınıp değerlendirmede kullanılmaktadir (Education, n.d.)

THE sıralamasında Uluslararası işbirliği, uluslararası öğrenci oranı ve uluslararası öğretim elemanı oranlarının her biri \%2,5 nispetinde sıralamada kullanılmaktadır ve kurumların kendi beyanı esas alınarak hesaplama yapılmaktadır. Öğretim elemanlarının endüstride görev alarak sundukları akademik katkılar da sıralamada kullanılmış ve $\% 2,5$ oranında değerlendirmeye alınmıştır. Bu husus da aynı şekilde kurum beyanı ile gerçekleşmektedir.

\begin{tabular}{|l|c|c|c|}
\hline Sıralama yapılan unsur & US News & THE & URAP \\
\hline Bilinirlik (Eğitim) & & 15 & \\
\hline Öğretim elmanı/öğrenci oranı & & 4,5 & \\
\hline Doktora öğrencisi/lisans öğrencisi oranı & & 2,25 & \\
\hline $\begin{array}{l}\text { Mezun edilen doktorant/akademisyen kadro } \\
\text { sayısı oranı }\end{array}$ & & 6 & \\
\hline Kurumsal gelir & & 2,25 & \\
\hline Bilinirlik (bilimsel) & 12,5 & 18 & \\
\hline ArGe kaynaklı gelir & & 6 & \\
\hline ArGe verimliliği & & 6 & \\
\hline Toplam bilimsel makale & & & 21 \\
\hline Atıf sayısı & 7,5 & 30 & 21 \\
\hline Toplam bilimsel yayın & 15 & & 10 \\
\hline Makale yayınlanan Dergilerin etki oranı & 27,5 & & 18 \\
\hline $\begin{array}{l}\text { Atıf yapan makalelerin yayınlandığı dergilerin } \\
\text { etki oranı }\end{array}$ & 15 & & 15 \\
\hline Uluslararası işbirliği & 10 & 2,5 & 15 \\
\hline Uluslararası öğrenci oranı & & 2,5 & \\
\hline Uluslararası akademik kadro oranı & 100 & 100 & 100 \\
\hline Yerel bilinirlik & & 2,5 & \\
\hline $\begin{array}{l}\text { Endüstriye yapılan akademik katkı kaynaklı } \\
\text { gelir }\end{array}$ & & 2,5 & \\
\hline Toplam & & & \\
\hline
\end{tabular}

Tablo 1. US News, Times ve URAP tarafından yapılan sıralamalarda kullanılan kriter ve oranları

US News'in yaptığı sıralamada ise Thomson Reuters tarafından yapılan ArGe "bilinirlik" araştırması sonuçları değerlendirilerek \%12,5 uluslararası ve \%12,5 de yerel ölçekte siralama hesaplamasina dahil edilmektedir. US News tarafından yapılan sıralamada atıf sayısı, bilimsel yayın, bilimsel makalelerin yayınlandığı dergilerin etki oranı, 
atıf yapılan makalelerin yayınlandığı dergilerin etki oranı gibi tamamen bilimsel dergi veri tabanlarından alınan rakamlarla hesaplamalar yapılmaktadır. US News tarafından yapılan sıralamada atıf sayıları \%7,5, toplam bilimsel yayın \%15, makalelerin yayınlandığı dergilerin etki oranı $\% 27,5$, atıf yapan makalelerin yayınlandığı dergilerin etki oranı \%15, uluslararası işbirliği \%10 bilinirlik de bilimsel $\% 12,5$ ve yerel de $\% 12,5$ olmak üzere toplamda $\% 25$ oraninda siralamaya dahil edilmektedir. US News siralama metodolojisinde kullanılan kriterlerin \%75'i uluslararası veri tabanlarında tutulan kayıtlardan elde edilmektedir. Üniversitenin mezunlarının iș bulma oranları, kurumun bilinirliği, kurumun fiziki imkanları gibi hususlar sıralamada dikkate alınmamaktadır.

Türkiye'de yapılan URAP sıralamasında ise toplam bilimsel makale (\%21), atıf sayısı (\%21), makale haricinde, konferans bildirisi, genel değerlendirme makaleleri, bilimsel mektuplar ve genel bilimsel değerlendirmelerden oluşan yayın sayısı (\%10), makalelerin yayınlandığı dergilerin etki oranı (\%18), atıf yapan makalelerin yayınlandığı dergilerin etki oranı (\%15) ve yabancı üniversitelerle işbirliğinden türetilen yayınlardan elde edilen uluslararası işbirliği (\%15) kriterleri esas alınarak sıralama yapılmaktadır. Buradan görüldüğü gibi URAP sıralamasında tüm kriterler uluslararası veri tabanlarında tutulan kayıtlardan elde edilmektedir. Üniversitenin mezunlarının iş bulma oranı, kurumun bilinirliği, yerel unsurlara ArGe katkısı, kurumun fiziki imkanları gibi hususlar sıralamada dikkate alınmamaktadir.

Sıralama yapılan her üç metoda bakıldığında Üniversite kalitesinde en kapsamlı kriter THE tarafindan yapılan değerlendirmedir. $\mathrm{Bu}$ değerlendirmede yapılan ArGe çalışmalarının yanında eğitimin kalitesinde etkili olan bilinirlik, öğretim elemanı başına düşen öğrenci sayısı, kurumda çalışma yapan doktora öğrencisi sayısı, akademisyen başına mezun edilen doktoralı eleman sayısı ve kurumun akademik imkanlarını kullanarak elde ettiği gelir kriter olarak kullanılmıştır. Kullanılan bu kriter üniversitelerin sadece ArGe kabiliyetini değil eğitim-öğretim yetkinliğini de kısmen ölçmektedir. US News ve URAP sıralama metodolojilerinde yapılan ölçümün daha çok Üniversitelerin ArGe yapabilirliğini ölçtüğü, eğitim-öğretim kalitesine dair bilginin kısıtlı olduğu söylenebilir. Üniversite eğitimi bir eğitim hizmeti vermeyi de içermektedir. Verilen bu hizmetin kalitesi yapılan çalışmalarla (Yavuz, Doç Selahattin, Akman, 2018) ölçülmektedir. Ancak bu hizmet kalitesi ulsularrası sıralamalarda kriter olarak yer bulmamaktadır.

\section{DEĞERLENDIRME}

Üniversite sıralamalarında sıralama kurumlarının çoğu yayın esasına dayanan kriterleri esas almakta, eğitim-öğretim kalitesine dayalı kriterler daha az oranda kullanılmaktadır. Hatta URAP değerlendirmesinde eğitim-öğretim kalitesine dayalı kriter bulunmamaktadır. THE sıralama sisteminde eğitim-öğretime ait sınırlı oranda kriter bulunmakla beraber mezunlarının istihdam edilmesi oranına dair bilgi verilmemektedir. Mezunlarının istihdam edildiği kurumlarda mesleki verimliliklerine dair de bir bilgi hiçbir sıralamada ölçülmemektedir.

Modern anlamda bilimsel yayın yapma ve bu yayınların kayıtlarının tutulması önemli ölçüde ABD ve İngiltere merkezli şirketler tarafından yapılmaktadır. Dolayısıyla bu firmaların tuttuğu ve türettiği veriler sıralamalarda kullanılmaktadır. Bu firmalar da ABD-İngiltere merkezli üniversitelerin belirlediği başlıklar altında kayırlar oluşturmaktadır. Bu durum da Dünyanın geri kalan ülkelerinin sıralama kriterlerine daha pasif katkı sağladığı anlamına gelmekte ve ABD-İngiltere merkezli üniversitelerin diğer üniversiteleri kendilerine benzetmek bakımından baskın bir ortam oluşturduğu şeklinde yorumlanabilir.

Sıralamaları kendi ArGe öncelikleri bakımından belirleyici unsur olarak kabul eden üniversiteler, Ülke öncelikleri ve diğer bölgesel önceliklerinin önemini de indirgeyebilmektedir.

Üniversiteler bir taraftan yapılan bu sıralamalarda üstlerde yer almak için çalışmalar yaparken diğer taraftan Yükseköğretim Kurulu kalite çalışmaları kapsamında yapılan düzenlemede puanlama ya da sıralama yapılmamaktadır. Bunun yerine kaliteye dair bazı unsurların uygun şekilde yapılıp yapılmadığı konuları incelenmektedir. Bu incelemede, öğretim üyesi/öğrenci oranı, kütüphane ve sosyal imkanlar, derslik ve laboratuvarlar gibi fiziki mekanlar, iyileştirme döngüleri, bölgesel etkileşim, çalışanların süreçlere katkı vermesi gibi kaliteyi doğrudan etkileyen unsurlar dikkate alınıp iyi uygulama örneği veya gelişmeye açık yönler şeklinde değerlendirmeye tabi tutulmaktadır. Sayısal bir yarışa döndürmeden kalite çalışmaları ülke genelinde bir sırlama yapılmasına yönelik geliştirilebilir.

Uluslararası sıralama kuruluşları bir taraftan kendi belirledikleri kriterler ölçeğinde sıralamalar yapıp, ülke ve üniversitenin kendi yapısına ait öncelikleri dikkate almamaktadır. Bu durumda üniversitelerimizin hem uluslararası bilim camiasından kopmayacak bir şekilde bu sıralamaları takip etmek hem de kendi öncelik ve dinamiklerine öncelik veren bir kalite ölçüm sistemini oluşturması gereği ortaya çıkmaktadır.

\section{KAYNAKLAR}

Education, T. H. (n.d.). https://www.timeshighereducation. com/world-university-rankings/methodology-world-university-rankings-2018.

Harvey, L. (2008). Rankings of Higher Education Institutions: A Critical Review. Quality in Higher Education, 14(3), 187207. https://doi.org/10.1080/13538320802507711

Pike, G. R. (2004). Measuring quality: A comparison of U.S. News rankings and NSSE benchmarks. Research in Higher Education, 45(2), 193-208. https://doi.org/10.1023/ B:RIHE.0000015695.84207.44

Ranking, U. N. (n.d.). https://www.usnews.com/education/ 
articles/rankings-methodologies.

Saisana, M., D’Hombres, B., \& Saltelli, A. (2011). Rickety numbers: Volatility of university rankings and policy implications. Research Policy, 40(1), 165-177. https://doi.org/10.1016/j.respol.2010.09.003

Taylor, P., \& Braddock, R. (2007). International university ranking systems and the idea of university excellence. Journal of Higher Education Policy and Management, 29(3), 245-260. https://doi.org/10.1080/13600800701457855

URAP. (n.d.). http://www.urapcenter.org/2018/methodology.php?q=3.

Yavuz, Doç Selahattin, Akman, Z. (2018). Üniversitelerin Sunmuş Olduğu Hizmetin Öğrenciler Tarafından Algılanması : Erzincan Üniversitesi İktisadi ve İdari Bilimler Fakültesi Örneği. Bartın Üniversitesi Íktisadi ve İdari Bilimler Fakültesi Dergisi, 9(17), 39-62. 